\title{
Effect of age and physical activity level on functional fitness in older adults
}

\author{
Hulya Donat Tuna • Ayse Ozcan Edeer • \\ Mehtap Malkoc • Gazanfer Aksakoglu
}

Received: 28 March 2009 /Accepted: 20 August 2009 /Published online: 4 October 2009

(C) European Group for Research into Elderly and Physical Activity (EGREPA) 2009

\begin{abstract}
It is difficult to distinguish between the effects of age and physical activity level in the functional fitness level of older adults. The objective of this study was to determine the effects of age and physical activity level on some functional fitness parameters in community-dwelling older adults. Two hundred twenty-nine elderly (111 female; 118 male) aged between $65-87$ years living in the Balçova municipality region were divided into two groups: the young elderly (65-69 years old) and the elderly (70 years old or over). The "seven-day physical activity recall questionnaire" was used to estimate physical activity level (PAL). The functional fitness evaluation included the body mass index (BMI), the lower body strength (LBS), the dynamic balance, and the aerobic endurance. The young elderly were significantly worse with regard to BMI and significantly better with regard to LBS, dynamic balance, and aerobic endurance than the elderly; in contrast, PAL did
\end{abstract}

\author{
H. Donat Tuna $(\bowtie)$ \\ Institute of Health Science, Dokuz Eylül University, \\ 35340 Inciralti-Izmir, Turkey \\ e-mail: hdonat23@hotmail.com \\ A. Ozcan Edeer $\cdot$ M. Malkoc \\ School of Physical Therapy and Rehabilitation, \\ Dokuz Eylül University, \\ 35340 Inciralti-Izmir, Turkey \\ A. Ozcan Edeer \\ e-mail: ayse.ozcan@deu.edu.tr \\ M. Malkoc \\ e-mail: mehtap.malkoc@deu.edu.tr \\ G. Aksakoglu \\ Department of Community Medicine, Dokuz Eylül University, \\ 35340 Inciralti-Izmir, Turkey \\ e-mail: gazanfer.aksakoglu@deu.edu.tr
}

not affect any of the functional fitness parameters. The young elderly showed worse BMI than the elderly when the age groups were less active. The young elderly showed better LBS and dynamic balance than the elderly when the age groups were more active. The young elderly showed significantly better aerobic endurance than the elderly in both the less and more active age groups. This study confirms that age affects functional fitness, whereas PAL generally does not. However, being more active is advantageous for the young elderly with regard to BMI, LBS, and dynamic balance.

Keywords Aging $\cdot$ Physical activity level $\cdot$ Functional fitness

\section{Background}

When used to describe older adults, the term "functional fitness" is usually used instead of "physical fitness". Functional fitness is defined as a sufficient physical fitness level to manage daily living activities safely and independently without fatigue $[1,2]$. The disability model needs to be known in order to understand functional fitness. This model posits only pathology or disease as reasons for poor functional fitness; recently, however, inactivity and disuse have been added as additional reasons [2].

A decline in functional capacity (strength, endurance, agility, and flexibility) is seen with advancing age and causes difficulties in daily living activities. Furthermore, older adults tend to be less active with advancing age, although it is well-known that physical activity is important for independent living, prevention of chronic health problems, and quality of life [4, 5]. Although functional losses (e.g., such as difficulties in walking, carrying packages, and climbing stairways) are related to aging, Brill PA stated that 
these losses are also affected by physical inactivity [5]. Insufficient activity causes a decrease in cardiovascular conditioning and exercise capacity, disuse atrophy, and sometimes cellular loss [1].

An active lifestyle is important in preventing decreases in functional capacity (and, indirectly, quality of life) with age. Westerterp KR stated that the aging process is slower in some older adults. His review suggests that physical activity may provide one explanation for this. He also stated that an individual's most recent physical activity level (PAL) is more important than one from 5 years prior. Increasing PAL in later life has important effects, whereas returning to a past PAL causes regression in physical capacity [6]. Therefore, public health policies and research concentrating on PAL decreases with age have recently gained importance [3]. Many studies have confirmed the benefits of physical activity and exercise in older adults, such as adaptive improvements in functional capacity, cardiac and muscular reserves, and motor control and coordination $[1,7,8]$.

Cohort studies prove that a regular, active lifestyle may slow down the decrease in mobility performance. Brach JS et al. demonstrated a significant relation between physical activity during a 14-year period and current functional status in older women. Therefore, physical activity has a significant role in maintaining functional capacity [9]. Buchman AS et al. hypothesized that regressions in motor function related to aging could be altered with physical activity. After 8 years of follow-up research, this researcher concluded that each additional hour of physical activity at baseline was associated with about a $5 \%$ decrease in the rate of motor function decline [10]. McGuire DK stated that inactivity has a more severe destructive effect than aging [11].

In addition to age, lessening of physical activity also contributes to the decline in functional capacity. Therefore, it is difficult to distinguish between the effects of age and PAL on functional fitness in older adults $[12,13]$. In this study, the objective was to determine the effects of age and PAL on functional fitness parameters in communitydwelling older adults, regardless of chronic health status.

\section{Methods}

\section{Subjects}

The subjects were recruited from older adults living in the Balçova municipality region. The address records of older adults aged 65 years and over were obtained from the local administrations of each distinct of the Balçova region with the permission of the governorship. All of the older adults were visited at their addresses and given information about the study. Older adult volunteers who fit the inclusion criteria were evaluated.

The inclusion criteria were: aged between $65-90$ years, physically independent (able to walk 20 meters without assistance or resting), absence of cognitive disorder or dementia, attaining at least 24 points for educated and 18 points for non-educated subjects on the mini mental state evaluation [14], not being in the recovery period for an acute illness, and absence of blindness or deafness. Additionally, older adults with any cardiac disorders such as resting angina, recurrent heart failure, recurrent/uncontrolled arrhythmia, or recent uncontrolled hypertension were excluded.

A total of 3,939 older adults were visited at home in order to provide information for this study. In all, 673 older adults were recorded as volunteers. Of these, 261 subjects came to the assessment after the phone call. Because of their health status, 32 subjects were removed from consideration before the assessment. Data from 229 participants were used for analysis.

Informed consent was obtained immediately prior to data collection. The Ethics Committee of the Dokuz Eylül University approved the study protocol.

\section{Procedure}

After the subjects were informed about the assessments, demographics related to age, sex, body mass index (BMI), medical history (chronic health status number), smoking habits, and other characteristics were recorded. The same physiotherapist carried out all assessments.

The seven-day physical activity recall questionnaire (7Day PARQ) was used to estimate the PAL of the individuals [15-18]. The interview-administered questionnaire takes $10-15 \mathrm{~min}$ to complete. Participants are asked about the number of hours spent on sleep (1.0 MET) and moderate (4.0 MET), hard (6.0 MET), and very hard (10.0 MET) activities during the last 7 days. Examples of activities in each category are provided, and the activities are recorded for weekend days and weekdays separately. The remaining amount of time is noted as time spent doing light activities. Thus, the total weekly or daily kilocalories or kilocalories/kilogram expenditure can be estimated. In this study, we used kilocalories/kilogram/day ( $\mathrm{kcal} / \mathrm{kg} /$ day).

The functional fitness evaluation included the body mass index in kilograms per meter square of height (BMI, $\mathrm{kg}$ / $\mathrm{m}^{2}$ ), the "30-second chair stand test" for lower body strength (LBS), the "8-feet up-and-go test" for agility/ dynamic balance, and the "6-minute walk test" (6MWT) for aerobic endurance, as described in the "Older adult fitness battery/The senior fitness test" by Rikli and Jones [2, 1921]. The number of full stands with arms crossed on chest completed in $30 \mathrm{~s}$ was recorded for the 30 -second chair 
Table 1 Characteristics of the study sample

\begin{tabular}{|c|c|c|c|}
\hline \multicolumn{2}{|l|}{ Characteristic } & Mean $\pm \mathrm{SD}(\min -\max )$ & Number (percentage) \\
\hline \multirow{2}{*}{\multicolumn{2}{|c|}{$\begin{array}{l}\text { Age (year) } \\
\text { Body mass index }\left(\mathrm{kg} / \mathrm{m}^{2}\right)\end{array}$}} & $70.4 \pm 4.3(65-87)$ & \\
\hline & & $27.8 \pm 4.5(17.5-39.6)$ & \\
\hline \multicolumn{2}{|l|}{ Physical activity level (kcal/kg/day) } & $35.3 \pm 2.7(32-51)$ & \\
\hline \multirow[t]{2}{*}{ Sex } & Female & & $111(48.5)$ \\
\hline & Male & & $118(51.5)$ \\
\hline \multirow[t]{2}{*}{ Marital status } & Married & & $180(78.6)$ \\
\hline & Single & & $49(21.4)$ \\
\hline \multirow[t]{3}{*}{ Occupation } & Housewife & & $81(35.4)$ \\
\hline & Retired & & $139(60.7)$ \\
\hline & Retired-working & & $9(3.9)$ \\
\hline \multirow[t]{6}{*}{ Education } & Illiterate & & $18(7.9)$ \\
\hline & Literate & & $17(7.4)$ \\
\hline & Primary school & & $92(40.2)$ \\
\hline & Middle school & & $22(9.6)$ \\
\hline & High school & & $51(22.3)$ \\
\hline & College & & $29(12.7)$ \\
\hline \multirow[t]{3}{*}{ Number of people living with at home } & Alone & & $25(10.9)$ \\
\hline & With one person & & $135(59.0)$ \\
\hline & With 2 or more people & & $69(30.1)$ \\
\hline \multirow[t]{5}{*}{ Chronic health status } & 0 & & $22(9.6)$ \\
\hline & 1 & & $43(18.8)$ \\
\hline & 2 & & $64(27.9)$ \\
\hline & 3 & & $48(21.0)$ \\
\hline & 4/over & & $52(22.7)$ \\
\hline \multirow[t]{3}{*}{ Smoking history } & Never smoked & & $110(48.0)$ \\
\hline & Past smoker & & $83(36.2)$ \\
\hline & Current smoker & & $36(15.7)$ \\
\hline
\end{tabular}

stand test (number/30 s). The test began with the subject seated with their back straight and feet flat on the ground in the middle of a chair with a height of $17 \mathrm{in}$. The test began on the go signal. If the subject was more than halfway up at the end of $30 \mathrm{~s}$, this was counted as a full stand. In the 8feet up-and-go test, the time required getting up from a seated position, walk 8 feet, turn, and return to the seated position was recorded in seconds (s). A chair without arms and a cone positioned at the end of the 8-foot distance from the chair were used for this test. The subject was seated in the chair with their hands on their thighs and their feet flat on the floor. On the go signal, the subject was instructed to walk as quickly as possible (without running) around the cone and back to the chair. A stopwatch was started with the go signal and stopped when the subject was seated with an erect posture. Before both tests, a demonstration was performed by the tester; the subject completed one or two practice trials. The $6 \mathrm{MWT}$ took place in a hospital corridor. The total 6-minute walk distance (6MWD) covered during the 6 min was recorded in meters $(\mathrm{m})$. Before the subjects began the 6MWT, the following standard explanation was provided: "walk as quickly as you can along the corridor for $6 \mathrm{~min}$ to cover as much ground as possible. You may stop if you have to, but continue again as soon as you are
Table 2 Functional fitness of the study sample

\begin{tabular}{|c|c|c|c|c|}
\hline Functional fitness & & Number & $\bar{X} \pm \mathrm{SD}$ & Min-max \\
\hline BMI $\left(\mathrm{kg} / \mathrm{m}^{2}\right)$ & & 229 & $27.8 \pm 4.5$ & $17.5-39.6$ \\
\hline \multirow[t]{2}{*}{ Strength (number/30 s) } & Lower extremity & 229 & $11.7 \pm 2.6$ & $5-20$ \\
\hline & Upper extremity & 229 & $14.8 \pm 3.2$ & $5-24$ \\
\hline Dynamic balance (s) & & 229 & $7.6 \pm 1.7$ & $4.3-13.1$ \\
\hline Aerobic endurance (m) & & 211 & $452.2 \pm 76.5$ & $261-648$ \\
\hline
\end{tabular}


Table 3 Effect of age on functional fitness parameters

\begin{tabular}{|c|c|c|c|c|c|c|c|c|}
\hline \multirow[t]{2}{*}{ Age } & \multicolumn{2}{|l|}{ BMI } & \multicolumn{2}{|l|}{ LBS } & \multicolumn{2}{|c|}{ Dynamic balance } & \multicolumn{2}{|c|}{ Aerobic endurance } \\
\hline & Poor $n(\%)$ & Good $n(\%)$ & Poor $n(\%)$ & Good $n(\%)$ & Poor $n(\%)$ & Good $n(\%)$ & Poor $n(\%)$ & Good $n(\%)$ \\
\hline Elderly & $72(67.9)$ & $34(32.1)$ & $61(57.5)$ & $45(42.5)$ & $57(53.8)$ & $49(46.2)$ & $65(67.7)$ & $31(32.3)$ \\
\hline Young elderly & $99(80.5)$ & $24(19.5)$ & $49(39.8)$ & $74(60.2)$ & $39(31.7)$ & $84(68.3)$ & $48(41.7)$ & $67(58.3)$ \\
\hline \multicolumn{9}{|c|}{$\mathrm{OR}=0.51(0.27<\mathrm{OR}<0.98), \mathrm{OR}=2.05(1.17<\mathrm{OR}<3.60), \mathrm{OR}=2.51(1.41<\mathrm{OR}<4.46), \quad \mathrm{OR}=2.93(1.60<\mathrm{OR}<5.37)$} \\
\hline
\end{tabular}

$* p<0.05$

able to". Standardized encouragement was provided every 30 s during each 6MWT with the following phrases: "you're doing well" and "keep up the good work". A stopwatch was used to measure the walking time.

\section{Statistical analysis}

The statistical analysis was done with the consultation of a specialist in the department of community medicine. We used the Statistical Package for Social Sciences (SPSS 11.0 version) for statistical analysis. Some demographic data (age, BMI, PAL) are shown as means with standard deviations (means $\pm \mathrm{SD}$ ), and minimum-maximum values have been added. Other demographic characteristics are given as numbers and percentages.

The relationships between functional fitness and age or PAL were evaluated via Mantel-Haenszel chi-square analysis using "Statcalc, Epi Info Version 6" [22].The subjects were divided into two groups with regard to age, physical activity level, and functional fitness. The two age groups were the subjects aged between 65-69 years (the young elderly) and aged 70 years or over (the elderly). The subjects were divided into two groups ("less active" and "more active") according to the mean physical activity level of overall study sample. Mean values were calculated separately for women and men. The less active group included subjects below the mean physical activity level of the same sex, and the more active group included subjects above the mean value of the same sex. The same procedure was used for dividing subjects according to scores in the "30-second chair stand test", "8-feet up-and-go test", and "6-minute walk test"; these groups are referred to as "poor" and "good". The mean value was used for division because the data have parametric features. The BMI ratings from the National Heart, Lung, and Blood Institute of the National Institutes of Health were used to divide the older adults' BMI into poor (out of the normal range) and good (within the normal range: $18.5-24.9 \mathrm{~kg} / \mathrm{m}^{2}$ ) groups. The level of significance was accepted at 0.05 for each analysis [23].

\section{Results}

Data from 229 participants were used for analysis. A total of 18 participants did not take the 6MWT because of high blood pressure measured before the test; the other functional tests were applied to 229 participants. Participants' demographic and other characteristics are summarized in Table 1.

In the distribution of subjects' chronic health status, 144 participants had musculoskeletal, 21 respiratory, 56 cardiovascular, 14 digestive system, 25 renal, bladder and urinary system, eight neurological, 24 mental or emotional, three blood, and 18 eye problems. Five patients had a history of cancer, 120 had hypertension, and 43 were diabetic.

The functional fitness levels of all subjects are given in Table 2. The effects of age and PAL on functional fitness parameters were investigated separately (Tables 3, 5, and 4).

Age showed a statistically significant effect on BMI, LBS, dynamic balance, and aerobic endurance. The young elderly had significantly worse BMIs than the elderly, whereas the young elderly were significantly better with regard to LBS, dynamic balance, and aerobic endurance than the elderly. There was no significant effect of PAL on these parameters (Tables 3, 4).

Table 4 Effect of physical activity level on functional fitness parameters

\begin{tabular}{|c|c|c|c|c|c|c|c|c|}
\hline \multirow[t]{2}{*}{ PAL } & \multicolumn{2}{|l|}{ BMI } & \multicolumn{2}{|l|}{ LBS } & \multicolumn{2}{|c|}{ Dynamic balance } & \multicolumn{2}{|c|}{ Aerobic endurance } \\
\hline & Poor $n(\%)$ & Good $n(\%)$ & Poor $n(\%)$ & Good $n(\%)$ & Poor $n(\%)$ & Good $n(\%)$ & Poor $n(\%)$ & Good $n(\%)$ \\
\hline Less active & $104(75.4)$ & $34(24.6)$ & $70(50.7)$ & $68(49.3)$ & $64(46.4)$ & $74(53.6)$ & $67(54.5)$ & $56(45.5)$ \\
\hline More active & 67 (73.6) & $24(26.4)$ & $40(44.0)$ & $51(56.0)$ & $32(35.2)$ & $59(64.8)$ & $46(52.3)$ & $42(47.7)$ \\
\hline & \multicolumn{2}{|c|}{$\begin{array}{r}\mathrm{OR}=1.10(0.57<\mathrm{OR}<2.10), \\
\chi_{\text {Yates }}{ }^{2}=0.02, p=0.89\end{array}$} & \multicolumn{2}{|c|}{$\begin{array}{c}\mathrm{OR}=1.31(0.75<\mathrm{OR}<2.31) \\
\chi_{\text {Yates }}{ }^{2}=0.75, p=0.39\end{array}$} & $\begin{array}{c}1.59(0.89<0 \\
X_{\text {Yates }}^{2}=2.3\end{array}$ & $\begin{array}{l}2.86) \\
p=0.12\end{array}$ & \multicolumn{2}{|c|}{$\begin{array}{c}\mathrm{OR}=1.09(0.61<\mathrm{OR}<1.96) \\
\chi_{\text {Yates }}{ }^{2}=0.03, p=0.86\end{array}$} \\
\hline
\end{tabular}


Table 5 Effect of age on body mass index in the less and more active groups
BMI

\begin{tabular}{|c|c|c|c|}
\hline PAL and age & Poor $n(\%)$ & Good $n(\%)$ & Total $n(\%)$ \\
\hline \multicolumn{4}{|l|}{ Less active } \\
\hline Elderly & $42(65.6)$ & $22(34.4)$ & $64(100.0)$ \\
\hline \multirow[t]{2}{*}{ Young elderly } & $62(83.8$ & $12(16.2)$ & $74(100.0)$ \\
\hline & \multicolumn{3}{|c|}{$\mathrm{OR}=0.37(0.15<\mathrm{OR}<0.89), \chi_{\text {Yates }}^{2}=5.16, p=0.02 *$} \\
\hline \multicolumn{4}{|l|}{ More active } \\
\hline Elderly & $30(71.4)$ & $12(28.6)$ & $42(100.0)$ \\
\hline \multirow[t]{2}{*}{ Young elderly } & $37(75.5)$ & $12(24.5)$ & $49(100.0)$ \\
\hline & \multicolumn{3}{|c|}{$\begin{array}{l}\mathrm{OR}=0.81(0.29<\mathrm{OR}<2.28) \\
\chi_{\text {Yates }}=0.04, p=0.84\end{array}$} \\
\hline \multicolumn{4}{|c|}{ Total $\mathrm{OR}=0.51 ; \mathrm{MH}$ weighted $\mathrm{OR}=0.52, \mathrm{CI}=0.27<\mathrm{MHOR}<0.98 ; \mathrm{\chi}_{\mathrm{MH}}{ }^{2}=4.08, p=0.04 *$} \\
\hline
\end{tabular}

$* p<0.05$

In order to further understand the cause of the age effect on functional fitness, the effects of age on functional fitness were also investigated separately in less active and more active groups of subjects.

When age groups were arranged according to PAL stratification, the young elderly had significantly worse BMI than the elderly in the less active group. In contrast, there were no statistically significant differences in BMI between the young elderly and the elderly in the more active group. The generalized Mantel-Haenszel test showed that the young elderly had significantly worse BMIs than the elderly (Table 5).

When age groups were arranged according to PAL stratification, the young elderly had significantly better LBS than the elderly in the more active group. In contrast, there were no statistically significant differences in LBS between the young elderly and the elderly in the less active group. The generalized Mantel-Haenszel test showed that the young elderly, when more active, had significantly better LBSs than the elderly (Table 6).

When age groups were arranged according to PAL stratification, the young elderly had a significantly better dynamic balance than the elderly in both PAL groups (lower significance in the less active group, $p=0.046$; Table 7).

When age groups were arranged according to PAL stratification, the young elderly had significantly better aerobic endurance than the elderly in both PAL groups (Table 8).

\section{Discussion}

The effects of age and PAL on functional fitness in older adults were investigated in our study. It is important that the Mantel-Haenszel analysis was used to interpret the effects of both age and PAL on functional fitness. A total of 229 older adults were enrolled in the study because most of the 3,939 older adults living in the Balçova municipality region were not willing to participate in the study. Therefore, the study sample was small and it was one of the study limitations. Many assessment methods have been developed to evaluate PAL during the last three decades. It is difficult to evaluate PAL because of its variable components, such as type, frequency, duration, and intensity. Additionally, activity level based on habits can vary during
Table 6 Effect of age on LBS in the less and more active groups

\begin{tabular}{|c|c|c|c|}
\hline PAL and age & Poor $n(\%)$ & Good $n(\%)$ & Total $n(\%)$ \\
\hline \multicolumn{4}{|l|}{ Less active } \\
\hline Elderly & $37(57.8)$ & $27(42.2)$ & $64(100.0)$ \\
\hline Young elderly & $33(44.6)$ & $41(55.4)$ & $74(100.0)$ \\
\hline \multicolumn{4}{|c|}{$\mathrm{OR}=1.70(0.82<\mathrm{OR}<3.54), \chi_{\text {Yates }}{ }^{2}=1.90, p=0.17$} \\
\hline \multicolumn{4}{|l|}{ More active } \\
\hline Elderly & $24(57.1)$ & $18(42.9)$ & $42(100.0)$ \\
\hline Young elderly & $16(32.7)$ & $33(67.3)$ & $49(100.0)$ \\
\hline \multicolumn{4}{|c|}{$\mathrm{OR}=2.75(1.08<\mathrm{OR}<7.10), \chi_{\text {Yates }}^{2}=4.56, p=0.03 *$} \\
\hline \multicolumn{4}{|c|}{ Total $\mathrm{OR}=2.05 ; \mathrm{MH}$ weighted $\mathrm{OR}=2.05, \mathrm{CI}=1.17<\mathrm{MHOR}<3.61 ; \chi_{\mathrm{MH}}{ }^{2}=6.42, p=0.01 *$} \\
\hline
\end{tabular}


Table 7 Effect of age on dynamic balance in the less active and more active groups

\begin{tabular}{|c|c|c|c|}
\hline \multirow[t]{2}{*}{ PAL and age } & \multicolumn{3}{|c|}{ Dynamic balance } \\
\hline & Poor $n(\%)$ & Good $n(\%)$ & Total $n(\%)$ \\
\hline \multicolumn{4}{|l|}{ Less active } \\
\hline Elderly & $36(56.3)$ & $28(43.8)$ & $64(100.0)$ \\
\hline \multirow[t]{2}{*}{ Young elderly } & $28(37.8)$ & $46(62.2)$ & $74(100.0)$ \\
\hline & \multicolumn{3}{|c|}{$\mathrm{OR}=2.11(1.01<\mathrm{OR}<4.43), \chi_{\text {Yates }}{ }^{2}=3.97, p=0.046^{*}$} \\
\hline \multicolumn{4}{|l|}{ More active } \\
\hline Elderly & $21(50.0)$ & $21(50.0)$ & $42(100.0)$ \\
\hline Young elderly & $11(22.4)$ & $38(77.6)$ & $49(100.0)$ \\
\hline \multicolumn{4}{|c|}{$\mathrm{OR}=3.45(1.28<\mathrm{OR}<9.47), \chi_{\text {Yates }}^{2}=6.37, p=0.01 *$} \\
\hline \multicolumn{4}{|c|}{ Total $\mathrm{OR}=2.51 ; \mathrm{MH}$ weighted $\mathrm{OR}=2.53, \mathrm{GA}=1.42<\mathrm{MHOR}<4.53 ; \chi_{\mathrm{MH}}{ }^{2}=10.56, p=0.00 *$} \\
\hline
\end{tabular}

$* p<0.05$

energy for vigorous exercise, although they have active life style. Thus, the effect of total PAL on functional fitness could be interpreted with our results.

According to the general analysis in our study, the young elderly have significantly worse BMIs than the elderly. However, PAL does not affect BMI. Through further analysis, we found that the lower activity levels of the young elderly caused the young elderly to have a worse average BMI than the elderly. Therefore, we suggest that the young elderly would have better BMIs if they were more active.

Visser $M$ et al. reported a decrease in total physical activity and mobility performance (6-meter walk, chair sit, and stand up tests) for 2,109 subjects (55-85 years old) 3 years later. The rate speed of mobility decrease was slowed by regular lifestyle activity. It is also emphasized that higher levels of both sporting and nonsporting (e.g., household work, walking) activities are associated with smaller decreases in mobility performance, regardless of the presence of chronic disease [28]. Our study also revealed that the lower body strength of the young elderly, as assessed by the chair sit- and stand-up test, is better than that of the elderly. However, further analysis showed that
Table 8 Effect of age on aerobic endurance in the less and more active groups

\begin{tabular}{|c|c|c|c|}
\hline \multirow[t]{2}{*}{ PAL and age } & \multicolumn{3}{|l|}{$6 \mathrm{MWD}$} \\
\hline & Poor $n(\%)$ & Good $n(\%)$ & Total $n(\%)$ \\
\hline \multicolumn{4}{|l|}{ Less active } \\
\hline Elderly & $37(68.5)$ & $17(31.5)$ & $54(100.0)$ \\
\hline Young elderly & $30(43.5)$ & $39(56.5)$ & $69(100.0)$ \\
\hline \multicolumn{4}{|c|}{$\mathrm{OR}=2.83(1.26<\mathrm{OR}<6.41), \chi_{\text {Yates }^{2}}^{2}=6.68, p=0.01 *$} \\
\hline \multicolumn{4}{|l|}{ More active } \\
\hline Elderly & $28(66.7)$ & $14(33.3)$ & $42(100.0)$ \\
\hline Young elderly & $18(39.1)$ & $28(60.9)$ & $46(100.0)$ \\
\hline \multicolumn{4}{|c|}{$\mathrm{OR}=3.11(1.19<\mathrm{OR}<8.22), \chi_{\text {Yates }}^{2}=5.61, p=0.02 *$} \\
\hline \multicolumn{4}{|c|}{ Total $\mathrm{OR}=2.93 ; \mathrm{MH}$ weighted $\mathrm{OR}=2.94, \mathrm{CI}=1.61<\mathrm{MHOR}<5.42 ; \chi_{\mathrm{MH}}^{2}=13.15, p=0.00^{*}$} \\
\hline
\end{tabular}


this trend was caused primarily by the more active the young elderly. Thus, PAL has important an effect on LBS that was hidden in our general analysis.

Steffen TM et al. investigated the relationship between dynamic balance and aerobic endurance with age and sex. When they compared groups of subjects in the three decades between 60 and 89 years, they found that average performance tended to decrease due to age in both sexes [28]. In parallel to this, the elderly in our study had significantly worse dynamic balance and aerobic endurance than the young elderly. Aging is one of the reasons for worsening dynamic balance and aerobic endurance. When age groups were arranged according to PAL stratification in our study, the difference between the young elderly and the elderly was negligible in the less active group ( $p=0.046$ ); in contrast, the difference was statistically significant in the more active group $(p=0.01)$. Thus, it seems that the more active the young elderly caused the young old group to exceed the old group with regard to dynamic balance.

These findings are important, because they show that PAL in addition to age may affect functional fitness parameters like BMI, LBS, and dynamic balance.

McGuire DK et al. assessed the $\mathrm{VO}_{2 \max }$ values of five subjects (50-51 years old) before and after 3 weeks of bed rest in 1966, after 8 weeks of training after the bed rest, and after 6 months of training 30 years later. These authors found that the $\mathrm{VO}_{2 \max }$ levels after 6 months of training reached the $\mathrm{VO}_{2 \max }$ levels assessed before the 3 weeks of bed rest; however, no patients reached their posttraining values from 1966 [10]. This study reveals the simultaneous effects of both age and physical activity on the cardiovascular system. Thus, the effect of 3 weeks of bed rest is worse than the effect of three decades of aging. We found that the young elderly, regardless of their activity level, demonstrated better aerobic endurance than the elderly. This difference may arise, because aerobic endurance requires more effort than the other functional fitness parameters. Therefore, the young elderly have better aerobic endurance than the elderly regardless of PAL.

\section{Conclusion}

Whereas BMI improves with aging, lower body strength, dynamic balance, and aerobic endurance worsen in the older population. Generally, PAL does not seem to affect these parameters; however, further analysis revealed that being more active is advantageous for the young elderly with regard to BMI, lower body strength, and dynamic balance.

Acknowledgment This study was carried out as part of project number 104 S519 (SBAG-2984) between January 7, 2005 and
January 7, 2008, and was primarily supported by TUBITAK (The Scientific and Technological Research Council of Turkey).

This study was edited by "American Journal of Experts" in English.

\section{References}

1. Daley MJ, Spinks WL (2000) Exercise, mobility and aging. Sports Med 29(1):1-12

2. Rikli RE, Jones CJ (1999) Development and validation of a functional fitness test for community-residing older adults. J Aging Phys Act 7:129-161

3. Hardman AE, Stensel DJ (2003) Assessing the evidence. Physical activity and health: the evidence explained. Routledge Taylor \& Francis, London, pp 3-17

4. Hardman AE, Stensel DJ (2003) Ageing, therapeutic exercise and public health. In physical activity and health: the evidence explained. Routledge Taylor \& Francis Group, London, pp 241-54

5. Brill PA (2004) Functional fitness in older adults. Human Kinetics, USA, pp 3-8

6. Westerterp KR (2000) Daily physical activity and ageing. Curr Opin Clin Nutr Metab Care 3(6):485-488

7. Tanaka H, Seals DR (1997) Age and gender interactions in physiological functional capacity: insight from swimming performance. J Appl Physiol 82(3):846-851

8. Goldspink DF (2005) Ageing and activity: their effects on the functional reserve capacities of the heart and vascular smooth and skeletal muscles. Ergonomics 48(11-14):1334-1351. doi:10.1080/ 00140130500101247

9. Brach JS, FitzGerald S, Newman AB, Kelsey S, Kuller L, VanSwearingen JM, Kriska AM (2003) Physical activity and functional status in community-dwelling older women. Arch Intern Med 163:2565-2571. doi:10.1001/archinte.163.21.2565

10. Buchman AS, Boyle PA, Wilson RS, Bienias JL, Bennett DA (2007) Physical activity and motor decline in older persons. Muscle Nerve 35(3):354-362. doi:10.1002/mus.20702

11. McGuire DK, Levine BD, Williamson JW, Snell PG, Blomqvist CG, Saltin B, Mitchell JH (2001) A 30-year follow-up of the Dallas bed rest and training study: II Effect of age on cardiovascular adaptation to exercise training. Circulation 104 (12):1358-1366. doi:10.1161/hc3701.096099

12. Hardman AE, Stensel DJ (2003) Exercise and aging. In Physical activity and health:the evidence explained. Routledge Taylor \& Francis, London, pp 189-203

13. Onder G, Penninx BWJH, Lapuerta P, Fried LP, Ostir GV, Guralnik JM, Pahor M (2002) Change in physical performance over time in older women: the women's health and aging study. J Gerontol 57A:289-293

14. McDowell I, Newell C (1996) Mental status testing, Measuring health: a guide to rating scales and questionnaire, 2nd edn. Oxford University Press, New York, pp 314-322

15. Blair SN, Haskell WL, Ho P et al (1985) Assessment of habitual physical activity by a seven-day recall in a community survey and controlled experiments. Am J Epidemiol 122:794-804

16. Sallis JF, Haskell WL, Wood PD et al (1985) Physical activity assessment methodology in the Five-City Project. Am J Epidemiol 121:91-106

17. Richardson MT, Ainsworth BE, Jacops DR, Leon AS (2001) Validation of the stanford 7-day recall to assess habitual physical activity. Ann Epidemiol 11:145-153. doi:10.1016/S1047-2797 (00)00190-3

18. Lamb SE, Jorstad-Stein EC, Hauer K, Becker C (2005) Development of a common outcome data set for fall injury prevention trials: the 
prevention of falls network Europe consensus. J Am Geriatr Soc 53:1618-1622. doi:10.1111/j.1532-5415.2005.53455.x

19. Morrow JR, Jackson AW, Disch JG, Mood DP (2005) Chapter 11 physical fitness and activity assessment in adults. "older adult fitness battery". In Measurement and evaluation in human performance, 3rd edn. Human Kinetics, Champaign, pp 258-67

20. Jones J, Rikli RE (2002) Measuring functional fitness of older adults. The Journal on active aging; March-April:24-30

21. Mobily KE, Mobily PR (1997) Reliability of the 60+ functional fitness test battery for older adults. J Aging Phys Act 5:150-162

22. Elwood JM (1992) Causal relationships in medicine. Oxford University Press, New York, pp 84-94

23. Aksakoğlu G (2001) Sağlıkta araştırma teknikleri ve analiz yöntemleri. D.E.Ü. Rektörlük Matbaası, İzmir

24. Hussey J (2005) Physical activity and its health benefits. In: Gormley J, Hussey J (eds) Exercise therapy-prevention and treatment of disease. Blackwell Publishing, Oxford, pp 4-5
25. Dwyer GB, Davis SE (2005) ACSM's health-related physical fitness assessment manual. Lippincott Williams \& Wilkins, Philadelphia, pp 2-4

26. Brach JS, Simonsick EM, Kritchevsky S, Yaffe K, Newman AB (2004) Health, aging and body composition study research group. The association between physical function and lifestyle activity and exercise in the health, aging and body composition study. J Am Geriatr Soc 52(4):502-509. doi:oi:10.1111/j.1532-5415. 2004.52154.x

27. Visser M, Pluijm SMF, Stel VS, Bosscher RJ, Deeg DJH (2002) Physical activity as a determinant of change in mobility performance: the Longitudinal Aging Study Amsterdam. J Am Geriatr Soc 50:1774-1781. doi:10.1046/j.1532-5415.2002.50504.x

28. Steffen TM, Hacker TA, Mollinger L (2002) Age- and genderrelated test performance in community-dwelling elderly people: six-minute walk test, Berg balance scale, timed up \& go test, and gait speeds. Phys Ther 82(2):128-137 